\title{
Acute Testis Toxicity of Bisphenol A Diglycidyl Ether in Sprague-Dawley Rats
}

\author{
Yun-jung Yang', Shin-young Lee ${ }^{2}$, Kyung-yong Kim³, Yeon-pyo Hong ${ }^{1}$ \\ 'Department of Preventive Medicine; ${ }^{2}$ Department of Urology; ${ }^{3}$ Department of Anatomy; \\ College of Medicine, Chung-Ang University
}

\begin{abstract}
Objectives: Bisphenol A diglycidyl ether (BADGE) is a liquid compound obtained by condensation of two molecules of epichlorohydrin with one molecule of bisphenol A. General and reproductive toxicity with BADGE has been reported higher than $1000 \mathrm{mg} / \mathrm{kg} / \mathrm{day}$. This study was performed to show the effects of acute exposure to BADGE below 1000 $\mathrm{mg} / \mathrm{kg} /$ day on the testis in adult male rats.

Methods: BADGE was administered by gastric lavage in a single dose of $500,750,1000$, and $2000 \mathrm{mg} / \mathrm{kg} / \mathrm{day}$ in 8 -week old male SPF Sprague-Dawley rats. The right testis was processed for light microscopic analysis. The left testis was homogenized and spermatids were counted to determine the daily sperm production and daily abnormal sperm production. The sperm count, sperm motility, and incidence of abnormal sperm were estimated in the epididymis. In testicular sections, the seminiferous tubules were observed for qualitative changes. The progression of spermatogenesis was arbitrarily classified as full-matured, maturing, and immature. The specimen slide was observed at 3 points and 10 seminiferous tubules were evaluated at each point.

Results: The male rats exposed to single oral dose of BADGE at 750,1000 , and $2000 \mathrm{mg} / \mathrm{kg} / \mathrm{day}$ were significantly increased the number of immature and maturing sperm on the testis. There were no significant differences with respect to sperm head count, sperm motility, and sperm abnormality in the BADGE treatment groups.

Conclusions: These results suggest that single oral exposure of BADGE $750 \mathrm{mg} / \mathrm{kg} / \mathrm{day}$ can affect adult male testis development.
\end{abstract}

Key words: Bisphenol a diglycidyl ether, Testis, Histology, Acute toxicity

J Prev Med Public Health 2010;43(2):131-137

\section{INTRODUCTION}

The compound, 2,2-bis (4-(2,3-epoxypropyl)phenyl) propane, commonly known as bisphenol A diglycidyl ether (BADGE, CAS no. 1675-54-3), is the reaction product of one mole of 2,2-bis(4-hydroxyphenyl) propane (bisphenol A, BPA) with two moles of epichlorohydrin [1]. BADGE and its oligomers are major components of epoxy resins [2].

The major application areas for use of epoxy resins are protective coatings (steel structures, pipes, ships tanks, automotive primers, and appliances) and civil engineering (industrial flooring), together accounting for $75 \%$ of the total use. Additional applications include composites (windmills, aircraft, and automotive), printed circuit boards, adhesives, and tooling. A relatively small amount of epoxy resin $(<10 \%)$ is used for the interior lining of food and drink cans in which BADGE is only a minor component [1]. When heating or preserving canned foods, hydrolyzed or chlorinated derivatives of
BADGE (BADGE $\cdot 2 \mathrm{O}, \mathrm{BADGE} \cdot \mathrm{H}_{2} \mathrm{O}$, BADGE $\cdot$ $\mathrm{Cl} \cdot 2 \mathrm{O}, \mathrm{BADGE} \cdot \mathrm{Cl}$, and $\mathrm{BADGE} \cdot \mathrm{HCl}$ ) have been shown to have migrated into food [3-5].

Some in vitro studies have suggested that BADGE has estrogenic effects [6,7]. In other reports, BADGE has been found to be a partial antagonist in the E-SCREEN assay [8,9]. In 1999, European Commission the Scientific Committee of Food (SCF) published a new review on the safety of BADGE and concluded that there was no evidence for a systemic tumorigenic effect of topically applied pure or technical grade BADGE [10]. However, these reports did not provide sufficient evidence to require a safety assessment of food-cancoating epoxy compounds [11].

While consumer exposure to BADGE from epoxy can coatings is generally well below the regulatory threshold, some concerns have been raised that BADGE could be an endocrine disrupting chemical with a potential to cause reproductive and development toxicologic effects. This led the European Commission to initiate an evaluation of available data on BADGE. 
The evaluation concluded that the currently available data from in vivo studies in laboratory mammals do not indicate that BADGE causes adverse effects on reproduction [12].

In single-dose oral toxicity tests with BADGE, a LD50 values were upper than $1000 \mathrm{mg} / \mathrm{kg}$ has been recorded in studies with rats, mice, and rabbits. In full-dose tests, the oral LD50 for a commercial BADGE-based epoxy resin were reported to be $11400 \mathrm{mg} / \mathrm{kg}$ in rats, $15600 \mathrm{mg} / \mathrm{kg}$ in mice, and $19800 \mathrm{mg} / \mathrm{kg}$ in rabbits [13]. However, the study of rats exposed with a single oral dose was presented the possibility that BADGE might be induced general and reproductive toxicity below $1000 \mathrm{mg} / \mathrm{kg} /$ day [14]. Accordingly, it would be very interesting to know the effects of BADGE below $1000 \mathrm{mg} / \mathrm{kg} /$ day on testis.

Possible approaches to the evaluation of testicular damage after treatment with a noxious substance include traditional mating studies and pregnancy outcome, sperm production and motility, and histopathology [15]. Although the histopathologic evaluation shows the disadvantages of being subjective and time-consuming [16], this is the traditional method used for the detection of testicular damage produced by physical or chemical insult [17] and a sensitive tool for the detection of potential adverse effects on the testicle [18].

In this study, we performed to show the testis effects of acute exposure from 500-2000 mg/kg/day of BADGE in adult male rats.

\section{METHODS AND MATERIALS}

\section{I . Chemicals}

BADGE and corn oil were purchased from SigmaAldrich Co. (St. Louis, MO, USA).

\section{Experimental Animals}

The developmental toxicity study was performed in accordance with the Good Laboratory Practice (GLP) guidelines for Animal Experiments of Chemon Co. Ltd. Specific pathogen-free (SPF) Sprague-Dawley rats at 7 weeks of age (25 males) were purchased from the Dae Han Biolink Co. Ltd. (Eunseong County, Chung cheongbuk-do, Korea). The rats were identified and singly housed in suspended wire cages. They were housed in an animal room controlled at $23 \pm 3^{\circ} \mathrm{C}$ relative humidity at $55 \pm 15 \%$ with a light/dark cycle of 12 hours (light from 20:00 to 08:00 hours) and given free access to food (Teklad Global $18 \%$ Protein Rodent Diet; Harlan Co. Ltd., Madison, WI, USA). After acclimatization to the light/dark cycle for 1 week, the experiment was started.

\section{Experimental Design}

Animals were segregated into 5 groups of 5 rats each. Allocation of animals to dose groups was done by body weight randomization to ensure equal weight distribution among the groups. One group was treated with corn oil, which served as the control. The control group received an equivalent amount of corn oil. Four groups were treated with BADGE 500, 750, 1000 and $2000 \mathrm{mg} / \mathrm{kg} /$ day in each. The doses were determined from previous results showing that an acute exposure to BADGE (1000 mg/kg/day) resulted in changes in the reproductive system [14].

Each concentration of BADGE was dissolved in corn oil and sonicated with $40^{\circ} \mathrm{C}$ and wrapped in foil to prevent photodegradation. The compound was administered by gavage in corn oil at a volume of approximately $10 \mathrm{~mL} / \mathrm{kg}$ of body weight. Thereafter, all animals were observed carefully for 14 days during which mortality, body weight, and gross behavioral changes were noted on the 1st, 3rd, 7th, and 14th days. Each group necropsy was conducted on the 14 th day.

\section{Observational Items}

\section{i) General observations}

The animals were observed once daily during the predosing period, twice daily for behavioral and/or clinical changes on the day of dosing, or more frequently when indicated by the response of the animals to the treatment and at least once daily thereafter for 14 consecutive days.

\section{ii) Body weight and testis weight record}

The weights of all of the animals were recorded daily and any abnormalities in gross behavioral changes or food and water intake were also registered. All animals were observed carefully for 14 days during which mortality, body weight, and gross behavioral changes were noted on the 1st, 3rd, 7th, and 14th days. Each group necropsy was conducted on the 14th day. The weights of the testes were reported as both absolute and relative weights (testis weight/body weight $\times 100$ ). 

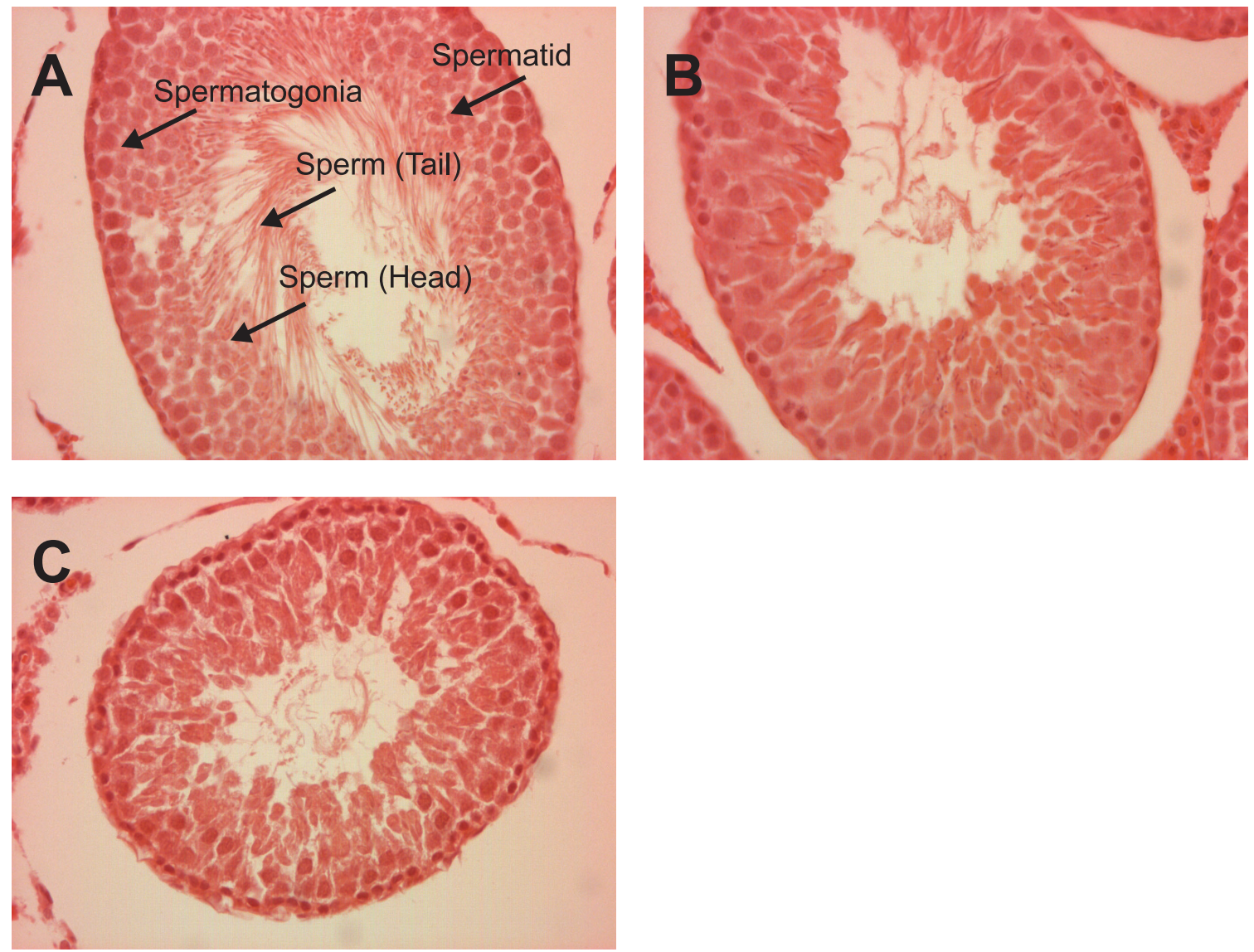

Figure 1. The classification of generation in seminiferous tubules.

A. Full-mature: spermatids with elongated ellipsoidal heads, and fully developed flagella tails, B. Maturing: spermatids with ellipsoidal heads, and slightly developed flagella tails, C. Immature: spermatids with oval shaped heads but without any developed flagella tails)

\section{iii) Histology of testis}

The testis was preserved and fixed in Bouin's solution for $24 \mathrm{hrs}$, and then washed several times with ethanol (70\%) before embedding in paraffin. The embedded tissue was sectioned in $5 \mu \mathrm{m}$ thicknesses, and stained with periodic acid schiff (PAS) and hematoxylin-eosin (H\&E).

Stained slides were analyzed by light microscopy (Olympus, Tokyo, Japan). All cross-sections of the seminiferous tubules in 1 transverse section of the testis were examined. In addition to the histologic changes, the progression of spermatogenesis was also evaluated (Figure 1). When the progression of spermatogenesis was not sufficient quantitatively, the seminiferous tubule was classified as an immature tubule, and when the progression was quantitatively sufficient, the tubule was classified as a fully-matured tubule. If the development of the seminiferous tubule was in between immature and fully-matured, it was classified as a maturing tubule. For evaluation of the progression of spermatogenesis, three areas of all cross sections of the testis were observed and
10 seminiferous tubules in each area were arbitrarily classified as fully-matured, maturing, and immature $[17,19]$.

\section{iv) Sperm toxicity}

All animals were assessed for sperm number, motility, and abnormalities. The right testes and cauda epididymis were homogenized separately for 2 min using IKA Ultra Turrax (model T25 basic Staufen, Germany) in $50 \mathrm{~mL}$ (testis) or $20 \mathrm{~mL}$ (cauda epididymis) of $0.9 \%$ saline containing $0.05 \%$ Triton X-100 and $0.01 \%$ thimerosal. Homogenates were diluted to approximately $1 \times 10^{6}$ sperm $/ \mathrm{mL}$, and counts from 4 hemocytometer chambers were counted and averaged.

\section{v) Statistical analysis}

Body weight, testis weight, and sperm toxicity were performed using the Kruskal-Wallis test. The frequency analysis between control and treatment groups was performed using $\chi^{2}$-test. All differences with a $p<0.05$ were considered significant. 


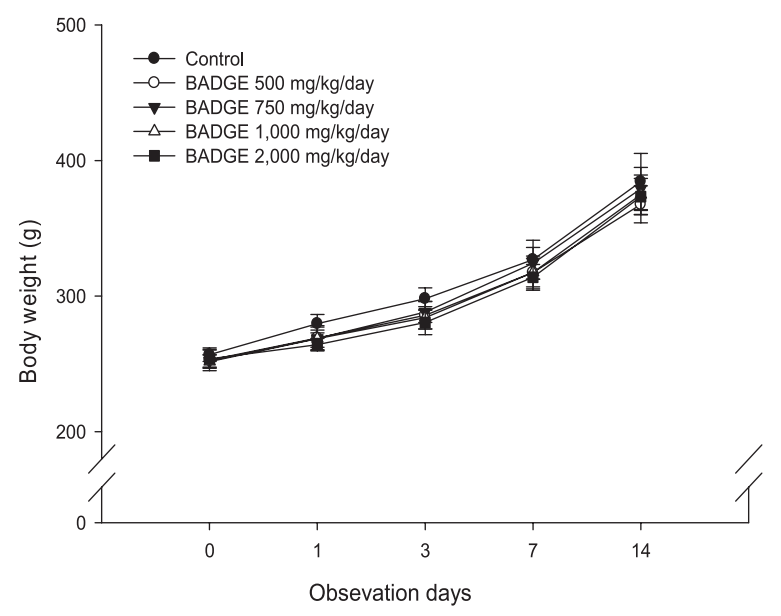

Figure 2. The changes of body weight in male rats exposed to BADGE. Values are means and standard deviations.

After exposure to BADGE, there were no significant differences in body weight.

BADGE: bisphenol-A diglycidyl ether.

Table 1. The changes of relative testis weight in male rats exposed to BADGE.

\begin{tabular}{cccccc}
\hline & Control & \multicolumn{4}{c}{ BADGE $(\mathrm{mg} / \mathrm{kg} / \mathrm{d})$} \\
\cline { 3 - 6 }$($ Corn-oil) & 500 & 750 & 1000 & 2000 \\
\hline Relative weight & $0.99 \pm 0.05$ & $0.96 \pm 0.09$ & $0.94 \pm 0.06$ & $0.89 \pm 0.03$ & $0.84 \pm 0.19$
\end{tabular}
of testis

Values are means and standard deviations. The relative testis weights of all treatment groups were not showed significant differences the means and standard deviations.

BADGE: bisphenol-A diglycidyl ether.

\section{RESULTS}

\section{General Observations}

After oral gavaging, one of the controls was observed to have soft stools; however, there were no deaths in the control and treatment groups. All BADGE-treated animals had slightly reduced food and water consumption on the day of administration, and the next day food and water consumption was lower in the BADGE 1000 and $2000 \mathrm{mg} / \mathrm{kg} /$ day-treated groups compared to the control group.

\section{Body Weight and Testis Weight}

The body weight and standard deviation of the control and $500,750,1000$, and $2000 \mathrm{mg} / \mathrm{kg} /$ day BADGEtreated groups showed $256.81 \pm 4.93,256.17 \pm 8.48$, $252.90 \pm 7.82,252.30 \pm 4.58,251.72 \pm 4.82$, and 253.69 $\pm 6.51 \mathrm{~g}$, respectively. After administration, the body weight of the control group was gradually increased. The
Table 2. The stage of generation in testis exposed to BADGE.

\begin{tabular}{lrrrcc}
\hline \multirow{2}{*}{$\begin{array}{l}\text { Stage of } \\
\text { generation }\end{array}$} & \multirow{2}{*}{ control } & \multicolumn{5}{c}{ BADGE $(\mathrm{mg} / \mathrm{kg} / \mathrm{d})$} \\
\cline { 3 - 6 } & & 500 & 750 & 1000 & 2000 \\
\hline Full-mature & 61 & 51 & 49 & 48 & 31 \\
Maturing & 84 & 91 & 86 & 85 & 47 \\
Immature & 5 & 8 & 15 & 17 & 72 \\
\hline$\chi^{2}$ & & 1.865 & 6.333 & 8.012 & 78.533 \\
p-value & & 0.39 & 0.04 & 0.02 & $<0.001$ \\
\hline
\end{tabular}

Incompleteness maturity was increased along with BADGE concentration. The proportion of immature tubules varied widely among the rats exposed to BADGE $2000 \mathrm{mg} / \mathrm{kg} / \mathrm{d}$. BADGE: bisphenol-A diglycidyl ether.

body weight of the BADGE treatment group was lower, but there was a similar weight gain to the control group (Figure 2).

The relative weights of the testes in the rats treated with BADGE were slightly lower than those of the control rats. There was no significant change in the weight of the testis at any of the doses treated (Table 1).

\section{Histologic Observation}

The testicular histology of the treated rats showed a dose-dependent effect of BADGE on spermatogenesis (Table 2). The proportion of immature tubules varied widely among the rats exposed to BADGE (2000 $\mathrm{mg} / \mathrm{kg} /$ day). The number of immature seminiferous tubules increased slightly in the rats treated with BADGE (500 mg/kg/day), but there was no difference in the immaturity of the seminiferous tubules between the control and the BADGE $500 \mathrm{mg} / \mathrm{kg} /$ day-treated group. In the testes of the rats exposed to BADGE (750 and $1000 \mathrm{mg} / \mathrm{kg} /$ day), histologic changes, including germ cell degeneration, were rare. In these groups, most seminiferous tubules were classified as maturing groups, but immaturity of the seminferous tubules was significantly higher than in the control group $(\mathrm{p}<0.05)$. In the testes of the rats exposed to BADGE (2000 $\mathrm{mg} / \mathrm{kg} /$ day), the number of immature seminiferous tubules was significantly higher than in the control group $(\mathrm{p}<0.001)$. Two rats from the BADGE $(2000 \mathrm{mg} / \mathrm{kg} /$ day) treatment group were shown to be immature of all observed seminferous tubules (Table 2).

\section{IV.Sperm Toxicity}

There were no significant differences in the BADGE treatment groups with respect to sperm head count, sperm motility, and sperm abnormalities. However, two 
Table 3. Sperm head count and motility in testis and epididymis. Two of BADGE $2000 \mathrm{mg} / \mathrm{kg} / \mathrm{d}$ treatment group was showed relatively lower sperm head count and sperm motility, and higher sperm abnormality than control group

\begin{tabular}{|c|c|c|c|c|}
\hline \multirow{2}{*}{$\begin{array}{l}\text { Group } \\
(\mathrm{mg} / \mathrm{kg} / \mathrm{d})\end{array}$} & \multicolumn{2}{|c|}{ Sperm head count } & \multirow{2}{*}{$\begin{array}{l}\text { Sperm } \\
\text { motility } \\
\text { positive } \\
(\%)\end{array}$} & \multirow{2}{*}{$\begin{array}{l}\text { Sperm } \\
\text { abnor- } \\
\text { mality (\%) }\end{array}$} \\
\hline & $\begin{array}{c}\text { Testis } \\
\left(\times 10^{6} / \text { testis }\right)\end{array}$ & $\begin{array}{c}\text { Epi. } \\
\left(\times 10^{6} / \text { epi }\right)\end{array}$ & & \\
\hline Control & $200.4 \pm 27.6$ & $80.6 \pm 6.5$ & $93.1 \pm 3.1$ & $4.4 \pm 4.5$ \\
\hline BADGE 500 & $199.6 \pm 14.0$ & $86.2 \pm 18.1$ & $84.8 \pm 16.3$ & $4.5 \pm 2.4$ \\
\hline BADGE 750 & $199.7 \pm 40.8$ & $92.5 \pm 13.2$ & $91.7 \pm 8.9$ & $4.0 \pm 1.4$ \\
\hline BADGE 1000 & $201.6 \pm 10.6$ & $84.5 \pm 18.3$ & $90.3 \pm 7.2$ & $5.0 \pm 2.7$ \\
\hline BADGE 2000 & $164.4 \pm 88.8$ & $58.3 \pm 28.3$ & $60.5 \pm 41.0$ & $18.8 \pm 22.5$ \\
\hline
\end{tabular}

BADGE: bisphenol-A diglycidyl ether; Epi: epididymis.

of the BADGE $(2000 \mathrm{mg} / \mathrm{kg} /$ day $)$ treatment group rats showed a relatively lower sperm head count and sperm motility, and higher sperm abnormalities than the control group (Table 3).

\section{DISCUSSION}

The purpose of the present study was to determine the effect of dose of BADGE acute exposure on the testis of adult male rats. There were no histologic changes in the testis between the control and BADGE $500 \mathrm{mg} / \mathrm{kg} / \mathrm{day}-$ treated group, but the BADGE 750, 1000, and 2000 $\mathrm{mg} / \mathrm{kg} /$ day groups had an increased number of immature and maturing sperm. The body weight and relative weights of the testes between the control and treated groups exhibited no statistical differences. This was partly due to the single oral exposure to BADGE in adult male rats and partly due to the inter-animal variability in responses for each dose group. The external appearance of the testis of the treated animals was unaffected after treatment.

The results of the histologic assessment, including the number of immature and maturing sperm, showed a dose-dependent increase according to the BADGE concentration on the rat testis, except for the BADGE $500 \mathrm{mg} / \mathrm{kg} /$ day-treated group. The histologic evaluation supported that the BADGE $250 \mathrm{mg} / \mathrm{kg} /$ day-treated male rats on a 2 -year oral gavage toxicity study had degeneration of seminiferous tubules [20]. Reproductive or developmental toxicity was reported at 375 $\mathrm{mg} / \mathrm{kg} /$ day of BADGE in male rats that were exposed in utero and during lactation [21]. Also, male rats with a single oral exposure to BADGE (1000 mg/kg/day) had a reduction in sperm number [14]. Therefore, a single oral exposure of BADGE interrupts physiologic spermatogenesis and leads to male infertility.
Sperm head count and sperm motility were decreased and sperm abnormality was increased in a dosedependent fashion, but there were no significant differences. Two rats in the BADGE $2000 \mathrm{mg} / \mathrm{kg} / \mathrm{day}$ group had slightly lower sperm motility and sperm number than the control group, but higher sperm abnormalities. The results of sperm toxicity were considered not individual- but group-related, so the BADGE $2000 \mathrm{mg} / \mathrm{kg} /$ day-treated group was evaluated for variations between individuals because each rat showed significant differences. Testicular sperm head counts might be a good indicator of spermatogenic damage [22]. An increase in sperm abnormality, and a decrease in sperm count and sperm motility are associated with decreased fertility $[23,24]$ and all these three spermatotoxic parameters are related to DNA fragmentation [25]. However, the testicular sperm head count was not decreased in the study. The reason was that testicular sperm head counts can overlook the effects of affecting earlier stages if the affected cells have not yet reached the stage of mature spermatids [16].

The estrogen receptor binding capacity of BADGE was low in an in vitro study [9], and the reproduction and developmental studies reported that BADGE does not affect reproduction or developmental endpoints [2629]. These limited or inadequate findings in experimental animals and the lack of epidemiologic data in humans indicated that BADGE could not be classified as a human carcinogen (group 3) [2]. However, evidence that BADGE could disrupt the endocrine system has been continuously reported. The single and repeatedly oral exposed adult male rats showed loss of spermatid in seminiferous tubules [14,20,21]. In addition, Bisphenol A bis (2,3-dihydroxypropyl) ether (BADGE. $2 \mathrm{H}_{2} \mathrm{O}$ ), as a metabolite from BADGE [30], disrupted testicular steroidogenesis by increasing Nur77 gene expression [31]. The male workers whose work was to spray epoxy resin hardening agents, including BADGE and mixed organic solvents, showed higher urinary BPA concentrations than controls, and depressed gonadotrophic hormones [32], although BPA is not a major metabolite of BADGE [33]. In our study, exposure of male rats to BADGE affected spermatogenesis following a single administration.

In order to investigate the functionality of the testis, clusterin expression should be measured. The earliest studies of clusterin were identified as a major protein in the secretory products of cultured rat Sertoli cells and in the fluid of ram rete testis [34,35]. Sertoli cells are essential for testis formation and spermatogenesis and are directly regulated by follicle stimulating hormone 
and testosterone, which are responsible for the initiation and maintenance of spermatogenesis [36,37]. The expression of clusterin mRNA was decreased in a dosedependent fashion in all groups of rats treated with BADGE [38]. Also, styrene-exposed rats were represent similar pattern of clusterin expression in testis [39]. Therefore, the clusterin expression on testis should be measured for evaluated physiologic effects.

According to these results, rats exposed to a single oral dose of BADGE $(750 \mathrm{mg} / \mathrm{kg} /$ day $)$ had an effect on the testis. Further studies are needed to determine the mechanisms of testicular toxicity of BADGE.

\section{ACKNOWLEDGMENTS}

This Research was supported by the Chung-Ang University Research Grants in 2009.

\section{REFERENCES}

1. Poole A, van Herwijene P, Weideli H, Thomas MC, Ransbotyn G, Vance C. Review of the toxicology, Human exposure and safety assessment for bisphenol A diglycidyl ether(BADGE). Food Addit Contam 2004; 21: 905-919.

2. International Agency for Research on Cancer (IARC). Reevaluation of some organic chemicals, hydrazine and hydrogen peroxide, IARC Monogr Eval Carcinog Risks Hum 1999; 71(Pt 3): 1285-1289.

3. Choi JC, Kyung SH, Lee GT, Lee KH. Simultaneous analysis method of BPA, BPF, BADGE, BFDGE and their degradation products in canned foods and food stimulants by HPLC. Kor J Food Sci Tech 2002; 34(2): 174-179. (Korean)

4. Hammarling L, Gustavsson H, Svensson K, Oskarsson A. Migration of bisphenol A diglycidyl ether (BADGE) and its reaction products in canned foods. Food Addit Contam 2000; 17(1): 937-943.

5. Pulgar R, Olea-Serrano MF, Novillo-Fertrell A, Rivas A, Pazos P, Pedraza V, et al. Determination of bisphenol A and related aromatic compounds released from bis-GMA-based composites and sealants by high performance liquid chromatography. Environ Health Perspect 2000; 108(1): 21-27.

6. Krishnan AV, Stathis P, Permuth SF, Tokes L, Feldman D. Bisphenol A: An estrogenic substance is released from polycarbonate flasks during autoclaving. Endocrinology 1993; 132(6): 2279-2286.

7. Perez P, Pulgar R, Olea-Serrano F, Villalobos M, Rivas A, Metzler M, et al. The estrogenicity of bisphenol a-related diphenylalkanes with various substituents at the central carbon and the hydroxy groups. Environ Health Perspect
1998; 106(3): 167-174.

8. Brotons JA, Olea-Serrano MF, Villalobos M, Pedraza V, Olea N. Xenoestrogens released from lacquer coatings in food cans. Environ Health Perspect 1995; 103(6): 608-612.

9. Olea N, Pulgar R, Perez P, Olea-Serrano F, Rivas A, Novillo Fertrell A, et al. Estrogenicity of resin-based composites and sealants used in dentistry. Environ Health Perspect 1996; 104(2): 298-305.

10. Scientific Committee on Food (SCF). Commission of the European Community: 1999 [cited 2009 July 20]. Opinion on bisphenol a diglycidyl ether (BADGE). Available from: URL: http://eceuropa.eu./food/fs/sc/saf/out28_en.pdf.

11. Nakazawa H, Yamaguchi A, Inoue K, Yamazaki T, Kato $\mathrm{K}$, Yoshimura $\mathrm{Y}$, et al. In vitro assay of hydrolysis and chlorohydroxy derivatives of bisphenol A diglycidyl ether for estrogenic activity. Food Chem Toxicol 2002; 40(12): 1827-1832.

12. Scientific Committee on Food (SCF). Commission of the European Community. 2003. [cited 2009 July 20]. Opinion of the Scientific Committee on Toxicity, Ecotoxicity and the Environment (CSTEE) on "Two Study Reports on Endocrine Disrupters by WRc-NSF and BKH Consulting Engineers" . European Commission. 2003. Available from: URL: http://ec.europa.eu/food/fs/sc/sct/out208_en.pdf.

13. Hine CH, Kodama JK, Anderson HH, Simonson DW, Wellington JS. The toxicology of epoxy resins. AMA Arch Ind Health 1958; 17(2): 129-144.

14. Im JU, Yang YJ, Lee TJ, Hong YP. Acute toxicity of administered Bisphenol a diglycidyl ether in male Sprague Dawley rats. Korean J Occup Environ Med 2006; 18(4): 318-326. (Korean)

15. Lamb IV JC. Fundamentals of male reproductive toxicity testing. In: Lamb IV JC, Foster PMD, editors. Physiology and Toxicology of Male Reproduction. San Diego, CA; Academic Press; 1988. p. 137-154.

16. Suter L, Clemann N, Koch E, Bobadilla M, Bechter R. New and traditional approaches for the assessment of testicular toxicity. Reprod Toxicol 1998; 12(1): 39-47.

17. Russell LD, Ettlin RA, SinhaHikim AP, Clegg ED. Staging for laboratory species. In: Evaluation of the Testis. $1^{\text {st }}$ ed. Clearwater: FL; Cache River Press; 1990. p. 62-194.

18. Takayama S, Akaike M, Kawashima K, Takahashi M, Kurokawa Y. A collaborative study in Japan on optimal treatment period and parameters for detection of male fertility disorders induced by drugs in rats. Int $J$ Toxicol 1995; 14(4): 266-292.

19. Lanning LL, Creasy DM, Chapin RE, Mann PC, Barlow NJ, Regan KS, et al. Recommended approaches for the evaluation of testicular and epididymal toxicity. Toxicol Pathol 2002; 30(4): 507-520.

20. Stebbins KE, Dryzga MD. Bisphenol A Diglycidyl Ether (BADGE): Subchronic Oral Gavage Toxicity Study In Fischer 344 Rats. Toxicology \& Environmental Research and Consulting. Midland, Michigan; The Dow Chemical Company, 2001. 
21. Hyoung UJ, Yang YJ, Kwon SK, Yoo JH, Myoung SC, Kim SC, et al. Developmental toxicity by exposure to bisphenol a diglycidyl ether during gestation and lactation period in Sprague-dawley male rat. J Prev Med Public Health 2007; 40(2): 155-161.

22. Cassidy SL, Dix K, Jenkins T. Evaluation of a testicular sperm head counting technique using rats exposed to dimethoxy-ethyl phthalate (DMEP), glycerol amonochlorohydrin $(\mathrm{GMCH})$, epichlorohydrin $(\mathrm{ECH})$, formaldehyde (FA), or methyl metanesulphonate (MMS). Arch Toxicol 1983; 53(1): 71-78.

23. Wyrobek AJ, Gordon LA, Burkhart JG, Francis MW, Kapp RW Jr, Letz G, et al. An evaluation of mouse sperm morphology test and other sperm tests in non human mammals. A report of the U.S. Environmental Protection Agency Gene-Tox Program. Mutat Res 1983; 115(1): 172.

24. Narayana K, D’Souza UJ, Seetharama Rao KP. Ribavirininduced sperm shape abnormalities in Wistar rat. Mutat Res 2002; 513(1-2): 193-196.

25. Tramer F, Rocco F, Micali F, Samdri G, Panfili E. Antioxidant systems in rat epididymal spermatozoa. Biol Reprod 1998; 59(4): 753-758.

26. Smith JA, Masters RE, Dawe IS. A Study of the Effect of TK 10490 on the Reproductive Function of One Generation in the Rat. Unpublished Report of Ciba-Geigy Ltd. Huntington Research Centre Report CB451/881081. 1989.

27. Hanley TR, Hagler AR, Sullivan VD, Stebbins KE. DGEBPA: Two Generation Oral Gavage Study in Sprague-Dawley Rats. Unpublished Report of the DOW Chemical Company. 1996.

28. Smith JA, Masters RE, Dawe IS. A Study of the Effect of TK 10490 on Pregnancy of the Rat. Unpublished Report of Ciba-Geigy Ltd. Huntington Research Centre Report CB442/87641. 1988.

29. Breslin WJ, Kirk HD, Johnson KA. Teratogenic evaluation of diglycidyl ether of bisphenol A (DGEBPA) in New Zealand white rabbits following dermal exposure. Fundam Appl Toxicol 1988; 10(4): 736-743.

30. Kostoryz EL, Eick JD, Glaros AG, Judy BM, Welshons
WV, Burmaster S, et al. Biocompatibility of hydroxylated metabolites of BISGMA and BFDGE. J Dent Res 2003; 82(5): 367-371.

31. Ahn SW, Nedumaran B, Xie Y, Kim DK, Kim YD, Choi HS. Bisphenol A bis(2,3-dihydroxypropyl) ether (BADGE.2H2O) induces orphan nuclear receptor Nur77 gene expression and increases steroidogenesis in mouse testicular Leydig cells. Mol Cells 2008; 26(1): 74-80.

32. Hanaoka T, Kawamura N, Hara K, Tsugane S. Urinary bisphenol $\mathrm{A}$ and plasma hormone concentrations in male workers exposed to bisphenol A diglycidyl ether and mixed organic solvents. Occup Environ Med 2002; 59(9): 625-628

33. Climie IJ, Hutson DH, Stoydin G. Metabolism of epoxy rein component 2,2-bis(4-(2,3-epoxypropoxy)phenyl) propane, the diglycidyl ether of bisphenol A (DGEBPA) in the mouse. Part II, Identification of metabolites in urine and faeces following a single oral dose of 14C-DGEBPA. Xenobiotica 1981; 11(6): 401-424.

34. Kissinger C, Skinner MK, Griswold MD. Analysis of Sertoli cell-secreted proteins by two-dimensional gel electrophoresis. Biol Reprod 1982; 27(1): 233-240.

35. Blaschuk O, Burdzy K, Fritz IB. Purification and characterization of a cell-aggregating factor (clusterin), the major glycoprotein in ram rete testis fluid. J Biol Chem 1983; 258(12): 7714-7720.

36. Ritzen EM. Hansson V and French FS. The Sertoli Cell. Burger H, de Kretser DM, editors. New York: Raven Press; 1981.p. 171-194.

37. McLachlan RI, O' Donnell L, Meachem SJ, Stanton PG, de Kretser DM, Pratis K, et al. Identification of specific sites of hormonal regulation in spermatogenesis in rats, monkeys, and man. Recent Prog Horm Res 2002; 57: 149179.

38. Kwon SK, Yang YJ, Chun YJ, Hong YP. Expression of clusterin on rat epididymis exposed to bisphenol A diglycidyl ether during in utero and lactation. Toxicol Environ Chem 2010; 92(2): 315-325.

39. Han JH, Choi CS, Kim MY, Chun YJ. Differential gene expression by styrene in rat reproductive tissue. $J$ Toxicol Environ Health A 2007; 70(15-16): 1259-1263. 